\title{
Nephrology a discipline evolving into complexity: between complex systems and philosophy
}

\author{
Natale G. De Santo ${ }^{1}$
}

Received: 7 November 2019 / Accepted: 12 November 2019 / Published online: 27 November 2019

(C) Italian Society of Nephrology 2019

\section{On specialists}

Science progresses through the work of specialists: they are at the same time the most indispensable and also the most despised, being charged of incapacity to catch the unity of knowledge. They are even described as narcissi who defend their individual originality by secluding themselves in smaller niches.

An example of this ambivalence was provided in the Heraclitean Fire: sketches from a Life Before Nature (1978) of Erwin Chargaff (1905-2002). He wrote that "if one or two persons decide to investigate on a rare beetle and find therein something interesting, their path will soon be followed by ten or more scientists. When the number of scientist investigating on the rare beetle will be around hundred they will create a scientific society and publish a journal. A scientific society generates a profession and a profession cannot be extinguished".

Murray Gell-Mann, who coined the word plectics (from the Greek stem plékō (braided and twisted) and founded (1984) the Santa Fe Institute in New Mexico, complained that "unfortunately in our society honors are accumulated only by those who study the general aspects of a fundamental problem". Thus, for him became necessary "to integrate specialized studies with an approximate overall look" (R. Chiaberge, Navigatori del sapere, 1999). The ideas of complexity, simplicity, regularity and randomness were thoroughly explained by Gell-Mann in The quarks and the Jaguar (1994), the quarks representing simplicity, the jaguar the complexity.

The 12th chapter of The Foucault's pendulum (1988) of Umberto Eco opens in a publishing house where Mr. Jacopo Belbo, who cares for university books, and Mr. Diotallevi

Natale G. De Santo

nataleg.desanto@unicampania.it

1 Emeritus Professor University of Campania Luigi Vanvitelli, Naples, Italy who cares for long-lasting books, are planning a new university faculty. Their list of possible departments includes comparative irrelevance, the art of subdividing one hair in four parts, impossibilia (impossible things), Gipsy city planning and bizarre disciplines (the art of cutting the broth, Antarctic architecture, crowd psychology in the Sahara desert, building machines to greet the old aunt).

\section{Introduction to complex thinking}

Edgar Morin, Basarab Nicholescu and Lima de Freitas in 1994 have drafted in the Monastery of Arrabida in Portugal The Charter of transdisciplinarity which should be considered as a permanent call to bridging disciplines which attracts the interest of scientists from all over the world. Transdisciplinarity was since then seen as a real space of synthesis across, between and beyond the disciplines.

For Edgan Morin "At the time of globalization specialization drives the progress of knowledge however, it also drives to breaking down knowledge which should be kept as a whole. The disjunction between disciplines hides the connections and the complexity of the whole human being. We are in extreme need of transdisciplinarity, to extract, assimilate and integrate knowledge which is broken down, separated, compartimentalized and fragmented. We have to find a way to have full knowledge of the zeitgeist and to push specialization to understand multidimensionality and much more to acquire a complex thought through an interdisciplinary route" (Les sept saviors nécessaires à l'éducation du future, 1999).

"The real problem-Morin says- "is to substitute the method which drives to know by disjunction and reduction with a new method obliging us to know by distinction and conjunction" (foreword for Mauro Ceruti'sIl tempo dellacomplessità, 2018). However, "we have to be aware that we are not yet landed in the society of knowledge, but rather in the society where knowledge is fragmented, and consists of 
various tesserae each separated from the others. Such separation does not allow us to bind them in order to understand the fundamental and global problems related to our personal lives as well as to our collective destinies". Although "disciplines are indispensable in our professional life to solve the general and fundamental problems we have to unify knowledge which is now dispersed in many disciplines. Thus, it is necessary to develop a more complex method of thinking and a more complex paradigm of knowing. Until we have the various knowledge, bound together according to the principles of complex knowledge, we will be unable to recognize the common weaving of things. We just see the threads that compose the tapestry. Identifying the individual threads does not allow to understand the overall design of the tapestry" (La Voie. 2011).

\section{Limits of disciplines}

We provide here just one example to justify adoption complexity for teaching medicine. In 1999, the Institute of Medicine of the United States of America published a report that suggested that between 44,000 and 98,000 people per year die of a preventable medical error [1]. There has been no progress with time and this indicating the complexity of medical practice and the difficulties in handling them with the traditional teaching-learning approach [2].

\section{The border with philosophy: Reductionism, Big Datasets and Omic platforms}

Teaching medicine with the method of complexity requires to develop the exchanges through the border with philosophy. This would provide physicians capable of the philosophical look as suggested by Karl Jaspers (1883-1969), Hans-George Gadamer (1900-2002) and Dietrich von Engelhardt (born 1941).

Reductionism has been the philosophical tool which has allowed the progress of medicine. Its origins coincide with that of science and medicine. Thales (born $636 \mathrm{BC}$ ) was the first reductionist. He identified water as the universal principle. Subsequently Anaximenes (586-525 BC) spoke of air, Heraclitus of Ephesus (540-480 BC) of fire, Empedocles of Akragas (492-423 BC) of air, water, earth and fire, Leucippus of Miletus (460-370 BC) of atoms. Hippocrates (450-377 BC) of blood, yellow bile, black bile and phlegm, Plato (428-347 BC) and Aristotle (384-322 BC) of fire, earth, air and water, Lucretius (98-55 BC) of atoms and void, Descartes (1596-1650) of human bodies as machines. Thus, complex problems have been dissected and answers have been given through analysis of single components. The approach has obvious limits and Systems Biology seems to hold the holistic potential to "explain the forest without studying the trees individually" [3]. This is indispensable when going from larger to smaller does not disclose the interactions between the components.

Big Datasets-still lacking as a perfect definition-are the product of mass digitization of started in the early years of the 90s of last century which hold the promise to change the future of health care. Because their High Volume, Velocity and Variety they require specific Technology and Analytical Methods. We are far from the possibility to utilize them to turn medicine from reactive into a proactive and achieve the 4P Medicine (predictive, preventive, personalized, participatory) driven by systems approach. It is not without reasons that the initiative "Big data to knowledge" was started at NIH.

Omic platforms now provide wide understanding of genome, transcriptome, proteome and metabolome utilizing information obtained through various techniques and much more is expected through the creation "of models that are predictive and adaptive" and "of institutes established and equipped specifically for systems biology" [4]. Recent example are provided by the study of coordinate behavior of coordinated protein response by means of the new algorithm known as the Systems Biology Triangle and by the use of systems biology of personalized nutrition.

\section{Nephrology a prototype of a discipline evolving into complexity}

Disciplines play a great role in disseminating and furthering knowledge. They are born-without aiming to eternity-in order to warrant the originality of the scientists who existed, exist and will exist in the future. In searching for originality, priority that means for a role in the world scientific enterprise they are forced to scrape smaller and smaller niches where they protect themselves and their contributions. Disciplines however, are like fractals their boundary regions are zones where exchanges are wider than those occurring in the internal zones (Ziman J. Real Science. What is and what it means, 2000).

Nephrology as a discipline was born in the 50s of the twentieth century although it had been existing long before. The discipline used to investigate, diagnose and take care of the so called renal diseases and of nephritides well before Richard Bright (1827). Nephrology developed in the boundary zones with other disciplines. It is a young discipline that effectively "entered the parlance of medicine in 1961". However, "it was the advent of maintenance dialysis that fueled its growth after the 1970" [5]. Nephrology has been characterized by the "the exponential information overload being generated. The pattern began in the 1960s has continued and 
been magnified by the specialty journals that have appeared since then" [6].

Systems biology is the last fruitful approach that drives present progress of nephrology. Many omics databases have been published which can be utilized for diagnostic purposes as well as to generate new hypotheses for clinical intervention as well as in research concerning IgA Nephropathy, and diabetic nephropathy. However, the most successful steps of nephrology were driven by two main ideas: (1) the classification of Chronic Kidney Disease (CKD) based on estimated glomerular filtration rate (eGFR) and (2) the identification of CKD as a systemic disease.

\section{On eGFR}

However, all originated from a study — sponsored by NIHon the possibility to slow progression of kidney diseases by low protein alimentation. "A major outcome of the study was the derivation of a formula to estimate glomerular filtration rate (GFR) from serum creatinine level. Validated and improved, this new predictive formula proved to be a clinically reliable index of kidney function in health and disease that would significantly affect the course of things to come" [7].

As Nobel Prize Eugenio Montale says in Before the trip "the unforeseen is our hope". eGFR was the unforeseen outcome of those studies. "As a result of this paradigm shift, the opportunity to improve outcomes changed from that of the thousands on maintenance dialysis therapy to the estimated ( $>10 \%$ of population) millions of individuals with CKD. The favorable response and rapid adoption of the new definition and classification of CKD worldwide by the nephrology community, as well as other medical disciplines and public health officials, was overwhelming. It was a transforming event that broadened the reach of nephrology well beyond its limited borders theretofore" [5].

\section{CKD a systemic disease amenable to cures}

The complex and systemic nature of CKD has been explored extensively during the last two decades. The relation between the kidneys and the other organs and their crosstalks [8] has been investigated. There were technological and analytical limitations as well as limitations due to the reductionist approach which presently governs the philosophy of medicine [8]. However, therapeutic algorithms capable of eliminating death and dialysis appear now feasible. A new tool for CKD may arise from "An age adapted definition" [9] and from studies on toxicity [10]. They may generate in the complexity a second new tool for diagnosis, stratification and cure of CKD because of the potential of new 'omics'.
Much more is expected through a systems biology approach utilizing omics techniques capable to unravel critical pathways that can be targeted for CKD prevention and therapy). Data already available indicate that the dream can soon be turned into reality. Advancement might be boosted by Social media in teaching and learning. An identical boost can be expected by studies on kidney stones the other systemic disease of nephrological interest.

\section{Conclusion}

Nephrology is rooted and evolves into complexity. It is nurtured by transdisciplinarity, it will be continuously shaped by analysis big data and algorithms. This will allow to take care of an increasing number of patients following guidelines emerging from complex analysis of a huge number of publication which no nephrologist could read/analyze personally. The benefits of reductionism (nephrology as a specialty) in clinical care however, can be preserved without renouncing to the advantages of complexity. "A discipline is a kind of organizing category since it introduces in the field of knowledge the division as well as specialization and a certain degree of autonomy" (Edgar Morin, La Tête bien faite, 2000).

Upgrading complexity of a discipline, at a certain extent, protects its autonomy, its know how its competences and the potential for integration with other disciplines. It helps in escaping the risks described by Schrödinger in What is life? (1947) and the caveats contained in the pamphlet of Erwin Chargraff (In dispraise of reductionism, 1997). Of course one shall never forget that knowledge on the DNA double helix, the Boson of Higgs, the expanding universe, the building of lasers etc. is the output of reductionism.

The paper supports the need to distinguish between a specialist and a truth seeker, as in the 1944 letter of Albert Einstein to Robert Thompton. The ties between science and philosophy are strong. This was extensively demonstrated in 2019 in PNAS by a group of investigators including Laplanea, Mantovani, Adolphs and others.

\section{Compliance with ethical standards}

Conflict of interest The author declares he does not have competing interests.

Ethical approval This article does not contain any studies with human participants performed by the author.

\section{References}

1. Kohn LT, Corrigan JM, Donaldson MS (2000) To err is human: building a safer health system. National Academy Press, Washington 
2. Leape L, Berwick D (2005) Five years after to err is human: what have we learned? J Am Med Inform Assoc 293:2385-2390

3. Ahn AC, Tewari M, Poon C-S, Phillips RS (2006) The limits of reductionism in medicine: could systems biology offer an alternative. PLoS Med 3(6):e20b. https://doi.org/10.1371/journ al.pmed.0030208

4. Macilwain C (2011) Systems biology: evolving into the mainstream. Cell 144:139-141

5. Eknoyan G (2017) Nephrology: What was then, but is not now. Am J Kidney Dis 69(1):129-136

6. Eknoyan G (2011) Remembrance of things past. Port J Nephrol Hypert 25(4):239-245

7. Levey AS, Bosch JP, Lewis JB, Greene T, Rogers N, Roth D (1999) A more accurate method to estimate glomerular filtration rate from serum creatinine: a new predictive equation. Ann Intern Med 130:461-470
8. Zoccali C, Vanholder R, Massy ZA et al (2017) The systemic nature of CKD. Nat Rev Nephrol 13:344-358

9. Delanaye P, Jager KJ, Bökenkamp A et al (2019) CKD: a call for an age-adapted definition. JASN. https://doi.org/10.1681/ ASN.2019030238

10. Perna A, Ingrosso D (2019) Homocysteine and chronic kidney disease: ongoing narrative. J Nephrol 32(5):635-637

Publisher's Note Springer Nature remains neutral with regard to jurisdictional claims in published maps and institutional affiliations. 